\title{
Review Article on Rhodanine Ring
}

\author{
Manar G. Salem, Yasmine M. Abdel Aziz, Marwa Elewa, Hosam A. Elshihawy, Mohamed M. \\ Said \\ Pharmaceutical Organic Chemistry Department, Faculty of Pharmacy, Suez Canal University, Ismailia, Egypt
}

\section{Received on: 13.11.2020}

Revised on: 31.11.2020

Accepted on: 03.12.2020

Correspondence Author:

Tel: +201115118244

E-mail address:

manar.galal@pharm.suez.edu.eg

\begin{abstract}
A review article described the chemistry of 4-thiazolidinones particularly rhodanine ring and different approaches for its reactions which included the modification of the ring. Besides, the reactivity of rhodanine ring which helped in the synthesis of different arylidenes at position 5 and carboxylic acids at position 3 The most reactive positions in 4-thiazolidinone are 3 and 5, which determine the major directions of heterocycle modification. Approaches to the synthesis of 3,5-disubstituted 4-thiazolidinones in general include two pathways. The first one was throughout the synthesis of 3,5-disubstituted 4thiazolidinones by different reactions in position 3 of the thiazolidinone cycle. The second was the synthesis of 3,5disubstituted 4-thiazolidinones by diverse reactions in position 5 of the thiazolidinone cycle Modification of 4-thiazolidinone cycle on positions 2, 3, 4 or 5 was successful to achieve synthetic products with a wide spectrum of pharmacological activity Currently 4thiazolidinones were considered as a new class of antidiabetic (insulinsensitizing) drugs and potent aldose reductase inhibitors, which possess the potential for the treatment of diabetes complications (cataract, nephropathy, neuropathy).
\end{abstract}

Keywords: Rhodanine; 4-Thiazolidinones; Methylene Carbon; Synthesis; SN2 Type.

\section{An Overview on 4-Thiazolidinones.}

Since the beginning of the 20th century, the pharmaceutical scientists considered the potential of 4-thiazolidinones as drugs. Therefore, sulfurand nitrogen-containing five- membered heterocyclic compounds such as rhodanines, thiazolidine-2,4-diones and thiazol-4(5H)-ones became interesting target structures for drug development and discovery. Several compounds of these classes are in clinical trials for diabetic complications, type II diabetes mellitus, antibacterial, antiviral, antimalarial, antifungal, antitumour activities and inhibitors of pancreatic cholesterol esterase (Paladhi, Jana et al. 2019, Sakr 2019). Modification of 4-thiazolidinone cycle on positions $2,3,4$ or 5 was successful to achieve synthetic products with a wide spectrum of pharmacological activity. Currently 4thiazolidinones were considered as a new class of antidiabetic (insulin sensitizing) drugs and potent 
aldose reductase inhibitors, which possess the potential for the treatment of diabetes complications (cataract, nephropathy, neuropathy). 4-Thiazolidinones are derivatives of thiazolidine (formula I) and with a carbonyl group in position 4 (formula II) (Figure 1). Substituents in positions 2, 3 , and 5 may be varied, but the greatest difference in structure and properties was exerted by the group attached to the carbon atom in position 2 (X in formula III). Such groups include oxygen (formula IIIA: 2,4-thiazolidinedione), sulfur (formula IIIB: rhodanine), imino (formula IIIC: pseudothiohydantoin) and hydrazine (formula IIID: 4-oxo-2-thiazolin-2-ylhydrazones of the aldehyde or ketone) (Brown 1961, Singh, Parmar

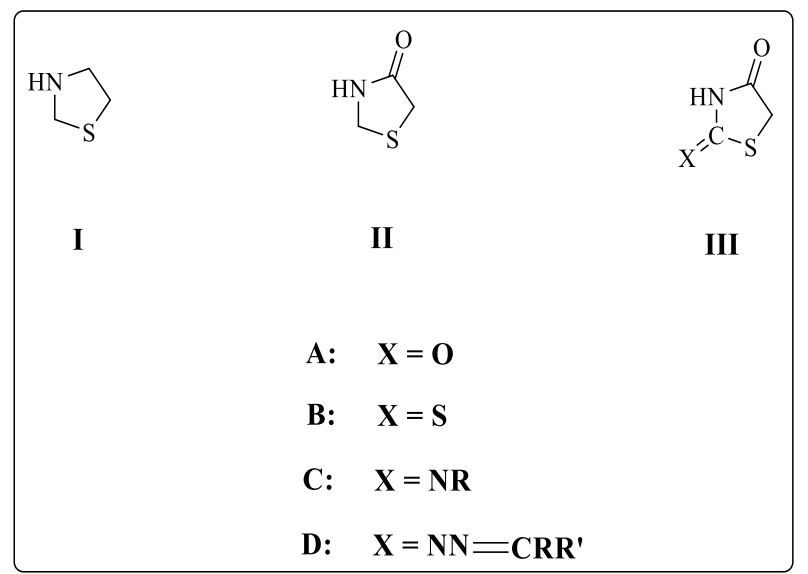

et al. 1981).

Figure 1: Derivatives of thiazolidine scaffold.

\section{The Reactivity of 4-Thiazolidinones.}

The most reactive positions in 4-thiazolidinone are 3 and 5, which determine the major directions of heterocycle modification. Approaches to the synthesis of 3,5-disubstituted 4-thiazolidinones in general include two pathways. The first one was throughout the synthesis of 3,5-disubstituted 4thiazolidinones by different reactions in position 3 of the thiazolidinone cycle. Secondly, was synthesis of 3,5-disubstituted 4-thiazolidinones by diverse reactions at thiazolidinone cycle position 5 .

The methylene group in position 5 of 4thiazolidinones is active enough to facilitate the chemical reaction. This could be attributed to the acidity of active methylene carbon atom that could be easily deprotonated. Besides, the conjugate base would be stabilized by resonance via delocalization of the negative charge to the more electronegative oxygen atom (Scheme 1). Therefore, most of the studied reactions of 4thiazolidinones focused on the modification of the mentioned position.

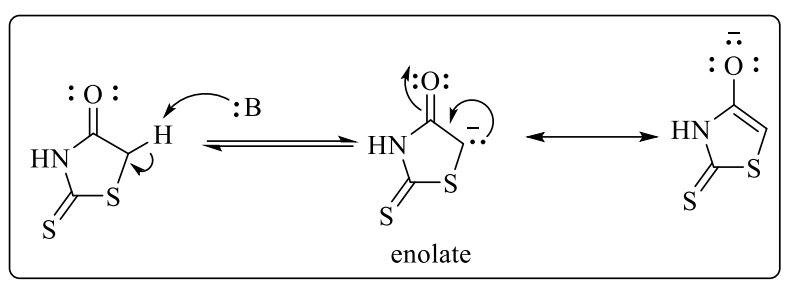

Scheme 1: Resonance stabilization of methylene.

\section{Reactions of 4-Thiazolidinones.}

\subsection{Reactions Dependent on the Nucleophilic Activity of the Methylene Carbon Atom.}

Aldol condensation is first reaction of this type to be investigated. Product of the reaction contained an $\alpha, \beta$-unsaturated compound (Scheme 2). When 5 -arylmethylenerhodanine was treated with alkali, it gave aldehyde odor. This was an evidence that aldol reaction of rhodanine derivatives was reversible (Brown, Bradsher et al. 1953).

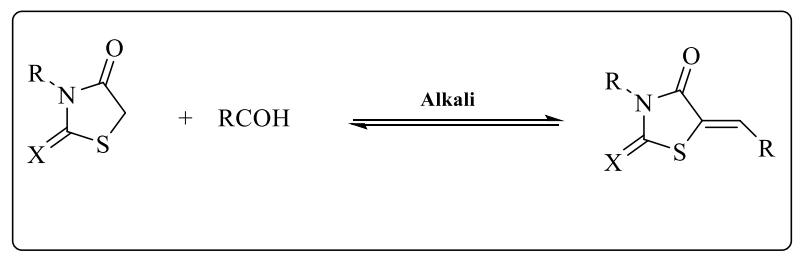

Scheme 2: Aldol condensation of the methylene group.

It is worthy to estimate that Knoevenagel reaction is a modified aldol condensation with a nucleophilic addition between an aldehyde or ketone and an active methylene compound in the presence of a basic catalyst, resulting in $\mathrm{C}-\mathrm{C}$ bond formation. The active hydrogen compound contained a $\mathrm{C}-\mathrm{H}$ bond which could be deprotonated by the basic catalyst. This reaction is usually followed by spontaneous dehydration resulting in an unsaturated product. This type of reaction allowed complex structures to be obtained with high efficiency and stereoselectivity. At the same time, the amount of waste produced was decreased significantly [5]. Knoevenagel reaction of 4-thiazolidinones with oxo compounds under basic catalysis yielded 5-arylidene-4thiazolidinones derivatives. This reaction constituted an efficient way to synthesize new biologically active substances. It was known that such reaction could be catalyzed by various bases. Numerous solvents were selected to optimize the reaction conditions (Scheme 3) (Table 1) (Momose, Meguro et al. 1991, Cantello, Cawthorne et al. 1994, Fresneau, Cussac et al. 1998, Lee and Sim 2000, Neogi, Lakner et al. 2003, Mahalle, Netankar et al. 2008, Pansare 2016). 


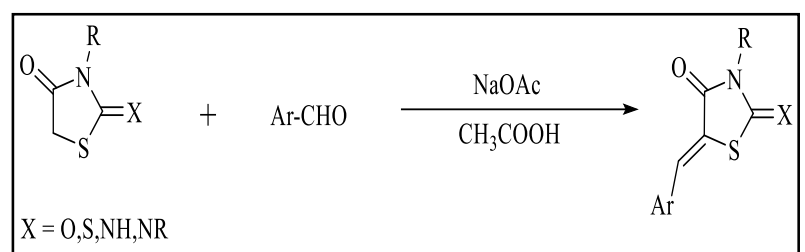

Scheme 3: Knoevenagel condensation of 4thiazolidinones with aromatic aldehydes.

Villemin and co-workers synthesized 5-arylidene derivatives 2 by reacting 3-methylrhodanine 1 with aromatic aldehydes on a surface of KF/Al2O3 in $\mathrm{CH} 2 \mathrm{Cl} 2$ under microwave irradiation (power 350 Watts, reaction time 4 min.) (Scheme 4). The same authors synthesized phosphonothiazolidinones 3 under analogous conditions (Villemin and Alloum 1993).

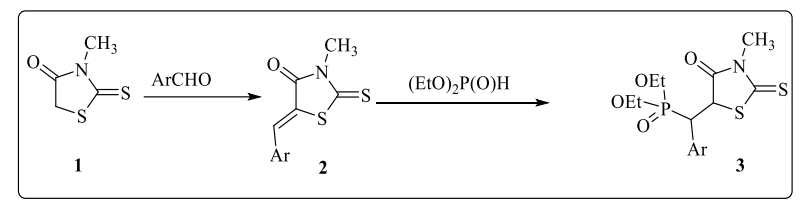

Scheme 4: Synthesis of 5-arylidene derivatives and phosphonothiazolidinones.

During the reaction of thiazolidinedione and dialkyloxalate in the presence of sodium alkoxide, one alkoxy group reacted giving compound $4(2,4-$ thiazolidinedione with glyoxalic acid residues in position 5) (Scheme 5) (Lesyk and Zimenkovsky 2004).

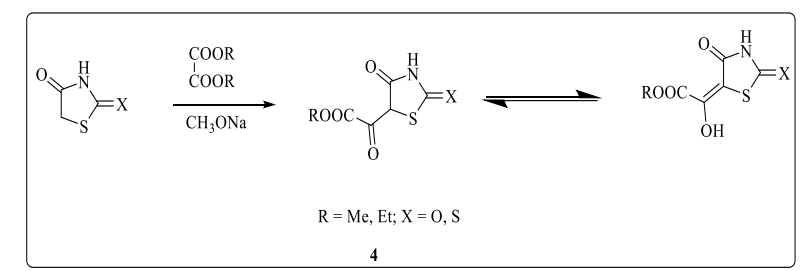

Scheme 5: Synthesis of 2,4-thiazolidinedione with glyoxalic acid residues in position 5.

Labile atom in position 5 of rhodanine molecule was the reason for the reaction with carboxylic acid ortho esters. Thus, 3-carboxymethylrhodanine 5 reacted with orthoformate ester in acetic anhydride leading to 3-carboxymethyl-5ethoxymethylidenerhodanine 6 . The reaction of compound 6 with primary and secondary amines in alcohol resulted in 5-aminomethylidene derivatives of 3-carboxymethylrhodanine 7 (Scheme 6) (Mezheritskii, Olekhnovich et al. 1976, Yoshitaka, Teruo et al. 1990).

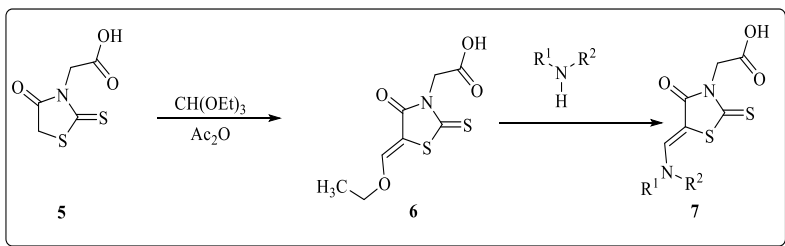

Scheme 6: Synthetic pathways of 3-carboxymethyl5-ethoxymethylidenerhodanine and 5-amino methylidene derivatives of 3-carboxymethyl rhodanine.

\begin{tabular}{|c|c|c|c|c|}
\hline Entry & Base & Solvent & $\begin{array}{l}\text { Time } \\
\text { (hr) }\end{array}$ & Yield $(\%)$ \\
\hline 1 & $\begin{array}{l}\text { Ammonium } \\
\text { acetate }\end{array}$ & Ethanol & 10 & 50 \\
\hline 2 & $\begin{array}{l}\text { Ammonium } \\
\text { acetate }\end{array}$ & $\mathrm{DMF}$ & 12 & 55 \\
\hline 3 & $\begin{array}{l}\text { Ammonium } \\
\text { acetate }\end{array}$ & Acetic acid & 11 & 75 \\
\hline 4 & $\begin{array}{l}\text { Ammonium } \\
\text { acetate }\end{array}$ & Methanol & 10 & 60 \\
\hline 5 & $\begin{array}{l}\text { Ammonium } \\
\text { acetate }\end{array}$ & Toluene & 11 & 50 \\
\hline 6 & $\begin{array}{l}\text { Sodium } \\
\text { acetate }\end{array}$ & Ethanol & 11 & 55 \\
\hline 7 & $\begin{array}{l}\text { Sodium } \\
\text { acetate }\end{array}$ & DMF & 10 & 58 \\
\hline 8 & $\begin{array}{l}\text { Sodium } \\
\text { acetate }\end{array}$ & Acetic acid & 6 & 90 \\
\hline 9 & $\begin{array}{l}\text { Sodium } \\
\text { acetate }\end{array}$ & Methanol & 12 & 65 \\
\hline 10 & $\begin{array}{l}\text { Sodium } \\
\text { acetate }\end{array}$ & Toluene & 10 & 60 \\
\hline 11 & Piperidine & Ethanol & 12 & 55 \\
\hline 12 & Piperidine & $\mathrm{DMF}$ & 11 & 58 \\
\hline 13 & Piperidine & Acetic acid & 12 & 80 \\
\hline 14 & Piperidine & Methanol & 12 & 60 \\
\hline 15 & Piperidine & Toluene & 13 & 52 \\
\hline
\end{tabular}

Table 1: Screening of catalyst, solvents, reaction time, and yield for

Knoevenagel condensation. All the reactions were carried out in equimolar amounts of each compound in $1 \mathrm{~mL}$ of solvent. 
The reaction of 5-unsubstituted rhodanine derivatives with substituted isothiocyanates in anhydrous acetic acid (Scheme 7) yielded 5carbamoylrhodanines $\mathbf{8}$.

$$
\begin{aligned}
& \mathcal{O}_{\mathrm{S}}^{\mathrm{O}} \mathrm{N}^{\mathrm{R}}=\mathrm{S} \\
& \underset{\mathrm{Ac}_{2} \mathrm{O}}{\mathrm{R} \text { NCY }} \\
& \underbrace{\mathrm{N}}_{\mathrm{S}}=\mathrm{S} \\
& \mathrm{Y}=\mathrm{O}, \mathrm{S}
\end{aligned}
$$

Scheme 7: Synthesis of 5-carbamoylrhodanines.

When pseudothiohydantoin moiety reacted with nitric acid, it gave a low yield of 5oximinopseudothiohydantoin. The same product was obtained in a better yield by the action of nitrous acid, to a solution of the pseudothiohydantoin (Scheme 8) (Sakr 2019). This could be an example of the reaction of 4thiazolidinones with nitrous acid and nitroso compounds.

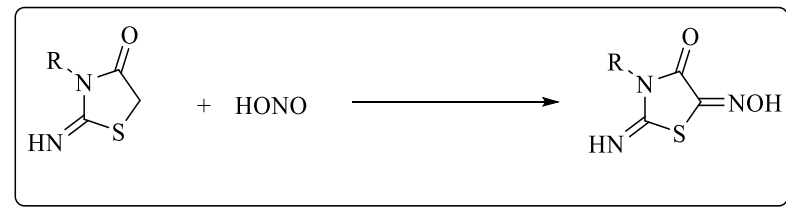

Scheme 8: Synthesis of 5-oximinopseudothiohydantoin through the reaction with nitrous acid.

Diazonium salts reacted with the 5-methylene group of 4-thiazolidinones through coupling reactions (Sakr 2019) (Scheme 9).

$$
\text { 空 }
$$

Scheme 9: The coupling reaction with diazonium salts.

\subsection{Reactions Dependent upon the Electrophilic} Activity of the Exocyclic Methylidine Carbon Atom.

\subsubsection{1,4-Addition to the Conjugated Carbonyl Group.}

The Grignard reagent was added to the conjugated carbonyl linkage of 5-benzylidenerhodanine and of 5-benzylidene-3-phenyl-2,4-thiazolidinedione, forming the 5-aralkyl derivatives. The carbanion of the Grignard reagent attacked the exocyclic electrophilic carbon atom of the 5benzylidenerhodanine 9 . Acidification of the anion yielded the 5-benzhydrylrhodanine 10 . Compound 10 was hydrolyzed by alkali to $\alpha$-mercapto- $\beta, \beta$ diphenylpropionic acid 11 (Scheme 10) (Mustafa, Asker et al. 1960).

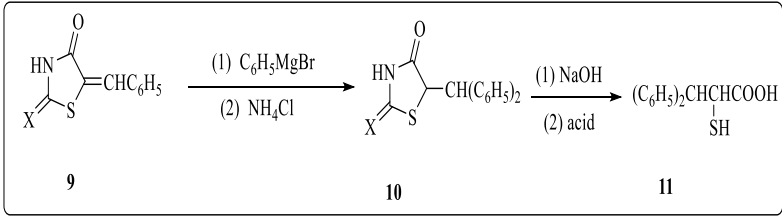

Scheme 10: 1,4-Addition to the conjugated carbonyl group.

\subsubsection{Displacement Reactions of $S_{N} 2$ Type.}

In this reaction, the electrophilic character of the exocyclic methylene carbon atom increased by the attachment of a potential anion, such as ethoxy group. Therefore, the displacement by other anions readily took place. For example, the displacement of alkoxy group by alkylthio or arylthio groups readily occurred. The alkoxy group of a 5-(1alkoxya1 kylidene) rhodanine 12 could be replaced by an alkylthio or arylthio groups and the corresponding derivative was produced 13 (Scheme 11). Zinc chloride in dioxane solution saturated with hydrogen chloride facilitated the reaction, and in several cases two isomers, believed to be cis and trans, were isolated ( $\mathrm{Sakr}$ 2019).

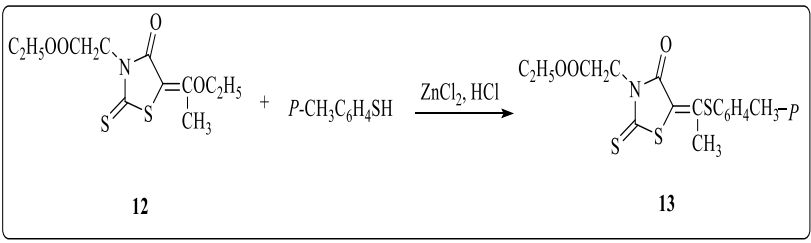

Scheme 11: Displacement reaction ( $S_{N} 2$ type).

\subsection{The Reduction of the Planar Conjugated System (C-5 Exocyclic Double Bond).}

The C-5 exocyclic double bond of 5-ene-4thiazolidinones formed the planar conjugated systems. This double bond could be reduced to the corresponding unconjugated structures. Challenging problem of such type of nonconjugated systems was the relative simplicity of enolization at position 5 under physiological conditions. This problem made the stereochemistry difficult to be maintained at this position (Scheme 12) ( $\mathrm{Yu}, \mathrm{Hu}$ et al. 2012). 


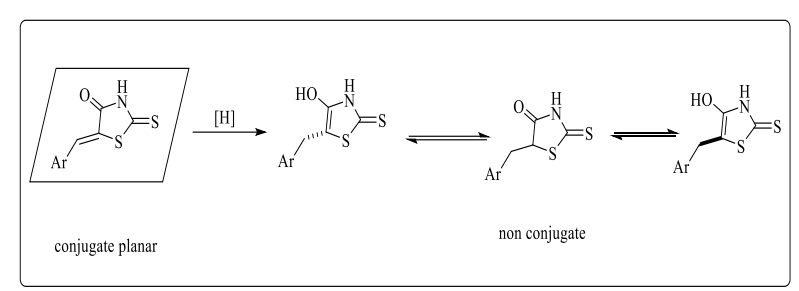

Scheme 12: The reduction of the planar conjugated system to unconjugated structure.

\section{Rhodanine Core}

Substituted rhodanines attracted a great attention due to their high impact in medicinal and pharmaceutical fields. Several compounds of this class are in clinical trials for diabetic complications, type II diabetes mellitus and inhibitors of pancreatic cholesterol esterase. In particular, the rhodanine derivative epalrestat was commercialized for the treatment of diabetic complications. The current study provided a cursory overview of the synthetic methods developed to access the rhodanine substrates and a summary of its applications to synthesize a broad range of differently substituted derivatives (Grummt, Weiss et al. 2007, Murugan, Anbazhagan et al. 2009, Véniant, Hale et al. 2010, Paladhi, Jana et al. 2019).

\subsection{Main Routes for the Synthesis of Rhodanine}

Methods used for the synthesis of rhodanine core and its derivatives were well known and described in this study (Song, Zheng et al. 2015, Kaminskyy, Kryshchyshyn et al. 2017). Chemical approaches to their synthesis were mostly similar to those used for other 4-thiazolidinone subtypes. The main methods of the rhodanine scaffold construction were illustrated in Scheme 13. The first pathway (i) was dithiocarbamate method. This method involved the reaction of carbon disulfide, ammonia or amine and $\alpha$-chlorocarboxylic acid through the stage of the dithiocarbamate formation. The second pathway (ii) was Holmberg method which based on the reaction between bis (carboxymethyl)-trithiocarbonate (thiocarbonylbis-thioglycolic acid) and primary amine. The third pathway (iii) was thiocyanate-based method. This method involved the reaction of thiocyanate and $\alpha$ halogenocarboxylic acids (Yarovenko, Nikitina et al. 2006). Development of the above-mentioned approaches in the last decades resulted in various multicomponent reactions (MCR) for the synthesis of target compounds. Modification of the dithiocarbamate method (i) led to the development of efficient synthetic protocols for the rhodanine derivatives. Besides, dithiocarbamate method is one of the MCR stages, for example in combination with Knoevenagel condensation. A fast and high yielding one-pot two-step process for the 5 -arylidenerhodanines combined the Holmberg method (ii) and the Knoevenagel condensation (Gabillet, Lecerclé et al. 2007, Alizadeh, Rostamnia et al. 2009, Radi, Botta et al. 2010, Jacobine and Posner 2011, Appalanaidu, Dadmal et al. 2015, Azizi, Hasani et al. 2015.

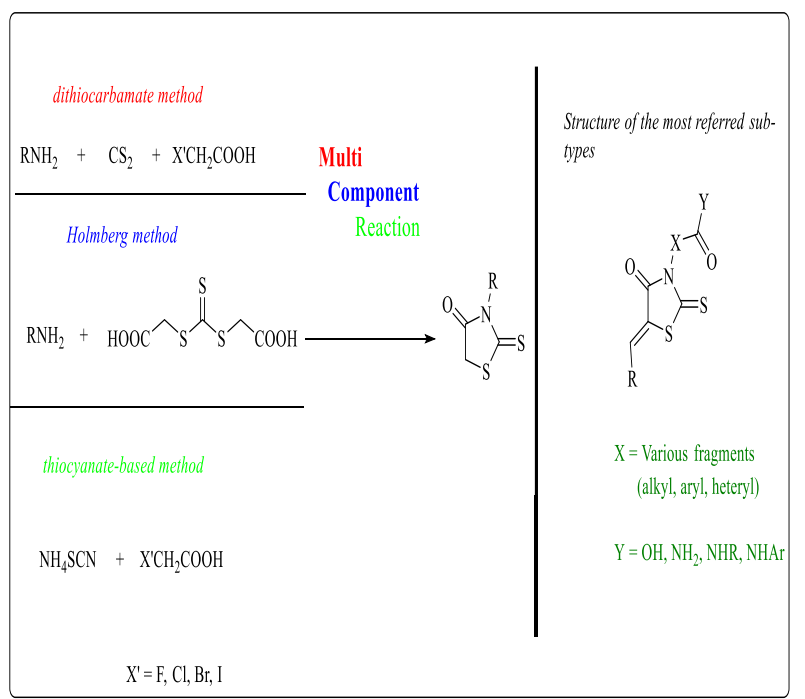

Scheme 13: The main methods of the rhodanine scaffold construction.

\subsection{Reactive Centers in Rhodanine Core}

The combination of several reactive centers in the structure of rhodanines made them an effective tool for the rational diversity-oriented synthesis. The main directions for active 5-ene-rhodanine based compounds optimization could be outlined in five domains. The first one was the elaboration of the fragment in position 5 (active methylene). The second was the introduction of the substituents in the N3 position (especially moieties with carboxylic group or its derivatives). The third was the transformation into related thiazolidinone derivatives (2-amino(imino)-4-thiazolidinones, 2,5-diylidene-4-thiazolidinones). The fourth was the incorporation into complex heterocyclic systems. The fifth was the combination with other pharmacologically attractive fragments within a hybrid pharmacophore approach (mixed pharmacophore) (Peng, Zhou et al. 1996, Takasu, Inoue et al. 2002, Pudhom, Kasai et al. 2006, Oh and Park 2011, Zhang, Wang et al. 2013). 


\section{References}

Alizadeh, A., S. Rostamnia, N. Zohreh and R. Hosseinpour (2009). "A simple and effective approach to the synthesis of rhodanine derivatives via three-component reactions in water." Tetrahedron Letters 50(14): 1533-1535.

Appalanaidu, K., T. Dadmal, N. J. Babu and R. M. Kumbhare (2015). "An improved one-pot multicomponent strategy for the preparation of thiazoline, thiazolidinone and thiazolidinol scaffolds." RSC advances 5(107): 88063-88069.

Azizi, N., M. Hasani, M. Khajeh and M. Edrisi (2015). "A straightforward and sustainable onepot, four-component synthesis of rhodanine derivatives." Tetrahedron Letters 56(10): 11891192.

Brown, F. C. (1961). "4-Thiazolidinones." Chemical Reviews 61(5): 463-521.

Brown, F. C., C. K. Bradsher and S. M. Bond (1953). "Some 5-Arylidene Derivatives." Industrial \& Engineering Chemistry 45(5): 1030-1033.

Bryhas, A. O., V. S. Matiychuk, T. Lis, V. Kinzhybalo, V. V. Smalius and M. D. Obushak (2013). "A four-step domino Knoevenagel-heteroDiels-Alder reaction." Tetrahedron Letters 54(42): 5667-5670.

Cantello, B. C., M. A. Cawthorne, G. P. Cottam, P. T. Duff, D. Haigh, R. M. Hindley, C. A. Lister, S. A. Smith and P. L. Thurlby (1994). "[[. omega.(Heterocyclylamino) alkoxy] benzyl]-2, 4thiazolidinediones as potent antihyperglycemic agents." Journal of medicinal chemistry 37(23): 3977-3985.

Fresneau, P., M. Cussac, J.-M. Morand, B. Szymonski, D. Tranqui and G. Leclerc (1998). "Synthesis, activity, and molecular modeling of new 2, 4-dioxo-5-(naphthylmethylene)-3thiazolidineacetic acids and 2-thioxo analogues as potent aldose reductase inhibitors." Journal of medicinal chemistry 41(24): 4706-4715.

Gabillet, S., D. Lecerclé, O. Loreau, M. Carboni, S. Dézard, J.-M. Gomis and F. Taran (2007). "Phosphine-catalyzed construction of sulfur heterocycles." Organic letters 9(20): 3925-3927.

Grummt, U.-W., D. Weiss, E. Birckner and R. Beckert (2007). "Pyridylthiazoles: Highly luminescent heterocyclic compounds." The Journal of Physical Chemistry A 111(6): 1104-1110.

Jacobine, A. M. and G. H. Posner (2011). "Threecomponent, one-flask synthesis of rhodanines (thiazolidinones)." The Journal of organic chemistry 76(19): 8121-8125.

Kaminskyy, D., A. Kryshchyshyn and R. Lesyk (2017). "5-Ene-4-thiazolidinones-An efficient tool in medicinal chemistry." European journal of medicinal chemistry 140: 542-594.

Lee, C. L. and M. M. Sim (2000). "Solid-phase combinatorial synthesis of 5-arylalkylidene rhodanine." Tetrahedron Letters 41(30): 57295732.

Lesyk, R. and B. Zimenkovsky (2004). "4Thiazolidones: centenarian history, current status and perspectives for modern organic and medicinal chemistry." Current Organic Chemistry 8(16): 1547-1577.

Mahalle, S. R., P. D. Netankar, S. P. Bondge and R. A. Mane (2008). "An efficient method for Knoevenagel condensation: a facile synthesis of 5arylidenyl 2, 4-thiazolidinedione." Green Chemistry Letters and Reviews 1(2): 103-106.

Mezheritskii, V., E. Olekhnovich, S. Luk'yanov and G. Dorofeenko (1976). "Orthoesters in organic synthesis." Izd. Rost. Univ., Rostov-on-Don: 94.

Momose, Y., K. Meguro, H. Ikeda, C. Hatanaka, S. Oi and T. SOHDA (1991). "Studies on antidiabetic agents. X. Synthesis and biological activities of pioglitazone and related compounds." Chemical and pharmaceutical bulletin 39(6): 14401445.

Murugan, R., S. Anbazhagan and S. S. Narayanan (2009). "Synthesis and in vivo antidiabetic activity of novel dispiropyrrolidines through $[3+2]$ cycloaddition reactions with thiazolidinedione and rhodanine derivatives." European journal of medicinal chemistry 44(8): 3272-3279.

Mustafa, A., W. Asker, S. Khattab, M. E. El Din Sobhy, A. M. Fleifel and K. Abu-Elazayem (1960). "Action of Grignard Reagents. XVII. 1 Action of Organomagnesium Compounds on 5Arylidene Derivatives of 3-Arylrhodanines, of 3-pTolyl-2, 4-thiazolidinedione and on 2-Arylidene-3 (2H)-4, 5-benzthianaphthenone-1, 1-dioxides." Journal of the American Chemical Society 82(8): 2029-2032.

Neogi, P., F. J. Lakner, S. Medicherla, J. Cheng, D. Dey, M. Gowri, B. Nag, S. D. Sharma, L. B. Pickford and C. Gross (2003). "Synthesis and structure-activity relationship studies of cinnamic acid-based novel thiazolidinedione antihyperglycemic agents." Bioorganic \& medicinal chemistry 11(18): 4059-4067. 
Oh, S. and S. B. Park (2011). "A design strategy for drug-like polyheterocycles with privileged substructures for discovery of specific smallmolecule modulators." Chemical Communications 47(48): 12754-12761.

Paladhi, S., B. Jana, S. Pathak and S. K. Mannab (2019). "Nucleophilic rhodanine, thiazolidine-2, 4dione and thiazol-4 (5H)-one substrates in asymmetric reactions." Organic Chemistry(part i): 256-292.

Pansare, D. N. (2016). "Development of novel inhibitors of bacterial enzyme mur b."

Peng, Z.-H., X.-F. Zhou, S. Carroll, H. J. Geise, B.-x. Peng, R. Dommisse, E. Esmans and R. Carleer (1996). "Structure of rhodanine cyanine dyes, spectroscopy and performance in photographic emulsions." Journal of Materials Chemistry 6(8): 1325-1333.

Pudhom, K., K. Kasai, H. Terauchi, H. Inoue, M. Kaiser, R. Brun, M. Ihara and K. Takasu (2006). "Synthesis of three classes of rhodacyanine dyes and evaluation of their in vitro and in vivo antimalarial activity." Bioorganic \& medicinal chemistry 14(24): 8550-8563.

Radi, M., L. Botta, G. Casaluce, M. Bernardini and M. Botta (2010). "Practical one-pot two-step protocol for the microwave-assisted synthesis of highly functionalized rhodanine derivatives." Journal of combinatorial chemistry 12(1): 200205.

Sakr, A. T. (2019). "Obesity and Type 3 Diabetes: Nutritional Approaches and Therapeutic Implication." Records of Pharmaceutical and Biomedical Sciences 3(2): 43-59.

Singh, S. P., S. S. Parmar, K. Raman and V. I. Stenberg (1981). "Chemistry and biological activity of thiazolidinones." Chemical Reviews 81(2): 175-203.

Song, M. X., C. J. Zheng, X. Q. Deng, Z. Y. Wei and H. R. Piao (2015). "The Synthesis and Anti-Bacterial Activities of N-Carboxymethyl Rhodanines." ChemInform 46(15): no-no.

Takasu, K., H. Inoue, H.-S. Kim, M. Suzuki, T. Shishido, Y. Wataya and M. Ihara (2002). "Rhodacyanine dyes as antimalarials. 1. Preliminary evaluation of their activity and toxicity." Journal of medicinal chemistry 45(5): 995-998.

Véniant, M. M., C. Hale, R. W. Hungate, K. Gahm, M. G. Emery, J. Jona, S. Joseph, J. Adams, A. Hague and G. Moniz (2010). "Discovery of a potent, orally active 11ß-hydroxysteroid dehydrogenase type 1 inhibitor for clinical study: Identification of (S)-2-((1 S, 2 S, 4 R)-Bicyclo [2.2. 1] heptan-2-ylamino)-5-isopropyl-5methylthiazol-4 (5 H)-one (AMG 221)." Journal of medicinal chemistry 53(11): 4481-4487.

Villemin, D. and A. B. Alloum (1993). "Phosphorus, Sulfur, Silicon Relat." Elem 79: 33.

Yarovenko, V. N., A. S. Nikitina, I. V. Zavarzin, M. M. Krayushkin and L. V. Kovalenko (2006). "A convenient synthesis of $\mathrm{N}$-substituted 2-thioxo1, 3-thiazolidin-4-ones." Synthesis 2006(08): 1246-1248.

Yoshitaka, O., M. Teruo, N. Mishiko, Y. Motoyuki, K. Norio, M. Kazumoto and T. Tsuuchiro (1990). "Preparation of 5alkylmethylidene-3-carboxymethyrhodanine derivaties and their aldose reductase inhibitory activity." Chem. and Pharm. Bull 38(7): 19111919.

$\mathrm{Yu}$, F., H. Hu, X. Gu and J. Ye (2012). "Asymmetric Michael addition of substituted rhodanines to $\alpha, \beta$-unsaturated ketones catalyzed by Bulky primary amines." Organic letters 14(8): 2038-2041.

Zhang, Y., S. Wang, S. Wu, S. Zhu, G. Dong, Z. Miao, J. Yao, W. Zhang, C. Sheng and W. Wang (2013). "Facile construction of structurally diverse thiazolidinedione-derived compounds via divergent stereoselective cascade organocatalysis and their biological exploratory studies." ACS Combinatorial Science 15(6): 298-308. 